\title{
Search for Natural Products Related to Regeneration of the Neuronal Network
}

\author{
Chihiro Tohda ${ }^{a}$ Tomoharu Kuboyama ${ }^{a, b}$ Katsuko Komatsu ${ }^{a, b}$ \\ ${ }^{a}$ Research Center for Ethnomedicines, Institute of Natural Medicine, and ${ }^{\mathrm{b}} 21$ st Century COE Program, \\ Toyama Medical and Pharmaceutical University, Toyama, Japan
}

\section{Key Words}

Neuritic atrophy $\cdot$ Synaptic loss $\cdot$ Dendrite $\cdot$ Axon .

Alzheimer's disease $\cdot$ Amyloid-beta $\cdot$ Ginseng $\cdot$ Withania somnifera. Ashwagandha. Coffee bean

\begin{abstract}
The reconstruction of neuronal networks in the damaged brain is necessary for the therapeutic treatment of neurodegenerative diseases. We have screened the neurite outgrowth activity of herbal drugs, and identified several active constituents. In each compound, neurite outgrowth activity was investigated under amyloid- $\beta$-induced neuritic atrophy. Most of the compounds with neurite regenerative activity also demonstrated memory improvement activity in Alzheimer's disease-model mice. Protopanaxadiol-type saponins in Ginseng drugs and their metabolite, M1 (20-O- $\beta$ - $D$-glucopyranosyl(20S)-protopanaxadiol), showed potent regeneration activity for axons and synapses, and amelioration of memory impairment. Withanolide derivatives (withanolide A, withanoside IV, and withanoside VI) isolated from the Indian herbal drug Ashwagandha, also showed neurite extension in normal and damaged cortical neurons. Trigonelline, a constituent of coffee beans, demonstrated the regeneration of dendrites and axons, in addition to memory improvement.
\end{abstract}

Copyright $\odot 2005$ S. Karger AG, Basel

\section{Introduction}

Despite the great number of ongoing investigations, neurodegenerative diseases remain incurable. The drugs currently available for dementia, such as donepezil, an acetylcholinesterase inhibitor, are efficacious in the temporary treatment of memory dysfunction, but do not prevent or reverse the underlying neurodegeneration [1]. In patients with Alzheimer's disease, neuritic atrophy and synaptic loss are considered the major causes of cognitive impairment, based on the results of neuropathological postmortem studies of the brain [2-4]. In the brains of patients suffering from other neurodegenerative diseases, such as Parkinson's disease, Huntington's disease, and Creutzfeldt-Jakob disease, neurite atrophy has also been observed [5-7]. Such atrophy leads to the destruction of neuronal networks, and subsequently to the fatal dysfunction of brain systems in these patients. The exclusion of, or at least a decrease in the magnitude of, the causes of each disease may prevent the progression of symptoms, but such inhibition is not associated with the repair of already severely damaged brain function. We hypothesized that the reconstruction of neuronal networks in the injured brain would be the most necessary step in the fundamental recovery of brain function, requiring neuritic regeneration and synaptic reconstruction.

\section{KARGER}

Fax + 41613061234 E-Mail karger@karger.ch www. karger.com 
Table 1. Natural medicine-oriented compounds which enhance neurite outgrowth

\begin{tabular}{|c|c|c|c|c|c|}
\hline Compound & Main botanical source & Cell used & Effective dose & Function & Reference \\
\hline Ginsenoside Rb1 & $\begin{array}{l}\text { Panax ginseng } \\
\text { Panax notoginseng }\end{array}$ & $\begin{array}{l}\text { rat cortical } \\
\text { neuron }\end{array}$ & $0.1-100 \mu M$ & $\begin{array}{l}\text { axon extension } \\
\text { synaptogenesis } \\
\text { memory improvement }\end{array}$ & 14,21 \\
\hline Metabolite $1^{*}$ & $\begin{array}{l}\text { (protopanaxadiol-type } \\
\text { saponins) }\end{array}$ & $\begin{array}{l}\text { rat cortical } \\
\text { neuron }\end{array}$ & $0.01-1 \mu M$ & $\begin{array}{l}\text { axon extension } \\
\text { synaptogenesis } \\
\text { memory improvement }\end{array}$ & 21 \\
\hline Withanolide A & Withania somnifera & $\begin{array}{l}\text { rat cortical } \\
\text { neuron }\end{array}$ & $1 \mu M$ & $\begin{array}{l}\text { axon extension } \\
\text { dendrite extension } \\
\text { synaptogenesis } \\
\text { memory improvement }\end{array}$ & $\begin{array}{l}36 \\
37\end{array}$ \\
\hline Withanoside IV & Withania somnifera & $\begin{array}{l}\text { rat cortical } \\
\text { neuron }\end{array}$ & $1 \mu M$ & $\begin{array}{l}\text { axon extension } \\
\text { dendrite extension } \\
\text { synaptogenesis } \\
\text { memory improvement }\end{array}$ & 36 \\
\hline Withanoside VI & Withania somnifera & $\begin{array}{l}\text { rat cortical } \\
\text { neuron }\end{array}$ & $1 \mu M$ & $\begin{array}{l}\text { axon extension } \\
\text { dendrite extension } \\
\text { synaptogenesis } \\
\text { memory improvement }\end{array}$ & 36 \\
\hline Trigonelline & coffee bean & $\begin{array}{l}\text { rat cortical } \\
\text { neuron }\end{array}$ & $30-100 \mu M$ & $\begin{array}{l}\text { axon extension } \\
\text { dendrite extension } \\
\text { memory improvement }\end{array}$ & 41 \\
\hline Honokiol & $\begin{array}{l}\text { Magnolia obovata } \\
\text { Magnolia officinalis }\end{array}$ & $\begin{array}{l}\text { rat cortical } \\
\text { neuron }\end{array}$ & $0.1-10 \mu M$ & neurite outgrowth & 43 \\
\hline $\begin{array}{l}\text { (-)-3,5-Dicaffeoyl- } \\
\text { muco-quinic acid }\end{array}$ & Aster scaber & $\mathrm{PC} 12$ & $1-10 \mu M$ & neurite outgrowth & 44 \\
\hline Catalpol & Rehmannia glutinosa & $\mathrm{PC} 12 \mathrm{~h}$ & $0.1-1 \mu \mathrm{g} / \mathrm{ml}$ & neurite outgrowth & 45 \\
\hline Geniposide & Gardenia jasminoides & $\mathrm{PC} 12 \mathrm{~h}$ & $0.1-10 \mu \mathrm{g} / \mathrm{ml}$ & neurite outgrowth & 45 \\
\hline Gardenoside & Gardenia jasminoides & $\mathrm{PC} 12 \mathrm{~h}$ & $0.1-10 \mu \mathrm{g} / \mathrm{ml}$ & neurite outgrowth & 45 \\
\hline Picroside I & $\begin{array}{l}\text { Picrorhiza } \\
\text { scrophulariiflora }\end{array}$ & PC12D & $10-100 \mu M$ & $\begin{array}{l}\text { potentiating } \\
\text { NGF-induced } \\
\text { neurite outgrowth }\end{array}$ & 46 \\
\hline Picroside II & $\begin{array}{l}\text { Picrorhiza } \\
\text { scrophulariiflora }\end{array}$ & PC12D & $0.1-100 \mu M$ & $\begin{array}{l}\text { potentiating } \\
\text { NGF-induced } \\
\text { neurite outgrowth }\end{array}$ & 46 \\
\hline Nardosinone & Nardostachys chinensis & PC12D & $0.1-100 \mu M$ & $\begin{array}{l}\text { potentiating } \\
\text { NGF-induced } \\
\text { neurite outgrowth }\end{array}$ & 47 \\
\hline
\end{tabular}

* 20-O- $\beta$ - $D$-Glucopyranosyl-(20S)-protopanaxadiol.

\section{Natural Products Enhancing Neurite Outgrowth}

Neurite outgrowth is the first step in the construction of the neuronal network, and neurite outgrowth activity has been investigated in many crude drugs. Of these extracts, several constituents have been identified as active compounds (table 1). It is critical that extended neurites have specific functions, such as axons and dendrites, and can make circuits by synaptic connections. However, the identification of axons and dendrites and the mea- 
surement of synaptogenesis have not been undertaken in studies of natural products, apart from in our research. Ginseng drugs, Ashwagandha and coffee beans contain interesting compounds with potent neurite regeneration, synaptic reconstruction and memory improvement activities.

\section{Ginseng Drugs}

Neurite Outgrowth Using Methanol Extracts and Isolated Saponins in SK-N-SH Cells

Ginseng, the root of Panax ginseng, is widely used as a tonic throughout the world, and is efficacious in the treatment of amnesia. In addition, significant improvement in learning and memory has been observed in brain-damaged [8,9] and aged rats [9] after the oral administration of Ginseng powder, and the major Ginseng saponins, ginsenoside $R b_{1}$ and $R g_{1}$, are known to improve spatial learning in normal mice [10]. Regarding the effects on neuronal cells, it has been shown that neurite outgrowth of cultured rat cerebral cortical neurons is enhanced by crude Ginseng saponins [11], and that ginsenoside $R b_{1}$ potentiates the nerve growth factor (NGF)-mediated neurite outgrowth of chick dorsal root ganglia $[12,13]$.

We tested the neurite outgrowth activity of methanol extracts of 6 types of Ginseng drugs and P. stipuleanatus plant material in SK-N-SH cells [14]. The methanol extracts of Ginseng (dried root of $P$. ginseng), Red Ginseng (steamed and dried root of $P$. ginseng), Notoginseng (dried root of $P$. notoginseng) and Ye-Sanchi (dried rhizome and root of $P$. vietnamensis var. fuscidiscus) increased neurite outgrowth, with the effects of Red Ginseng and Ye-Sanchi being particularly significant.

Thirty saponins were isolated from Ye-Sanchi and structurally elucidated $[15,16]$. Oleanolic acid-type saponins were also isolated from Kouzichi (dried rhizome of $P$. japonicus var. major from Hubei province) [17], and 19 saponins (ginsenosides $\mathrm{Rb}_{1}, \mathrm{Rb}_{3}, \mathrm{Rg}_{1}$ and $\mathrm{Re}$, notoginsenosides $\mathrm{R}_{4}$, Fa and $\mathrm{R}_{1}$, Yesanchinoside J, 20-O-glc-ginsenoside $\mathrm{Rf}$, majonoside $\mathrm{R}_{2}$, (24S)-pseudoginsenoside $\mathrm{RT}_{4}$ and $\mathrm{F}_{11}$, vina-ginsenoside $\mathrm{R}_{1}, \mathrm{R}_{2}$ and $\mathrm{R}_{6}$ from YeSanchi, notoginsenoside $R_{2}$, ginsenoside $R_{2}$ and Ro, chikusetsusaponin IVa from Kouzichi) were tested. Protopanaxadiol (ppd)-type saponins, ginsenosides $R b_{1}$ and $\mathrm{Rb}_{3}$, and notoginsenosides $\mathrm{R}_{4}$ and Fa significantly extended the neurites in SK-N-SH cells at a concentration of $100 \mu M$, and their activity increased dose-dependently. On the other hand, protopanaxatriol, ocotillol and oleanolic acid-type saponins showed no effect [14]. This sug- gests that ppd-type saponins are active compounds. Ginseng, Red Ginseng, Notoginseng and Ye-Sanchi, which showed neurite outgrowth activity, have been demonstrated to contain comparatively rich ppd-type saponins in our quantitative study [18]. This suggested that the effects of these drugs could be mainly attributed to ppdtype saponins. However, Zhuzishen (dried rhizome of $P$. japonicus var. major from Yunnan province) and a rhizome of $P$. stipuleanatus, which inhibited cell viability, may contain some cytotoxic compounds.

\section{Effect of M1, a Metabolite of Protopanaxadiol-Type}

Saponins, on A $\beta$ (25-35)-Induced Memory Impairment, Axonal Atrophy and Synaptic Loss in Mice

When taken orally, ppd-type saponins are mostly metabolized by intestinal bacteria to ppd monoglucoside, 20$O$ - $\beta$ - $D$-glucopyranosyl-(20S)-protopanaxadiol (M1) [19, 20] (fig. 1). As Ginseng is generally taken orally, a metabolite of ppd-type saponins, M1, should be investigated to determine the active constituent of Ginseng responsible for its major effects. We therefore conducted experiments to determine whether treatment with ginsenoside $\mathrm{Rb}_{1}$, as a representative of ppd-type saponins, and its metabolite, M1, can induce recovery from memory disorder, axonal atrophy, and synaptic loss induced by the active fragment of the amyloid- $\beta$ peptide $(A \beta(25-35))$ [21].

Male ddY mice (6 weeks old) were prepared to create a mouse model of Alzheimer's disease (AD). Seven days after an i.c.v. injection of $A \beta(25-35)$, ginsenoside $R b_{1}$ $(10 \mu \mathrm{mol} / \mathrm{kg}), \mathrm{M} 1(10 \mu \mathrm{mol} / \mathrm{kg})$, donepezil hydrochloride (DNP, $0.5 \mathrm{mg} / \mathrm{kg}$ ), or the vehicle (tap water) was administered orally once daily for 14 days. Mice were trained in the water maze for 7 days starting 14 days after the i.c.v. administration of $A \beta(25-35)$ (fig. 2a). The escape latency to find the platform in the $A \beta(25-35)$-injected group significantly increased compared with the saline-injected group, whereas the escape latencies of the groups administered ginsenoside $R b_{1}$ and $M 1$ p.o. significantly decreased as compared with the vehicle-administered group. The donepezil-administered group showed no significant shortening of the escape latency.

In the retention test (fig. 2b), the number of crossings over a previous platform position was significantly decreased in the $A \beta(25-35)$-injected group compared with the saline-injected group. The number of crossings recovered after treatment with ginsenoside $\mathrm{Rb}_{1}$ and $\mathrm{M} 1$. Treatment with donepezil showed the smallest effect in the retention test. All mice showed normal swimming performance and a constant increase in body weight. Locomotor activity did not differ among groups. 


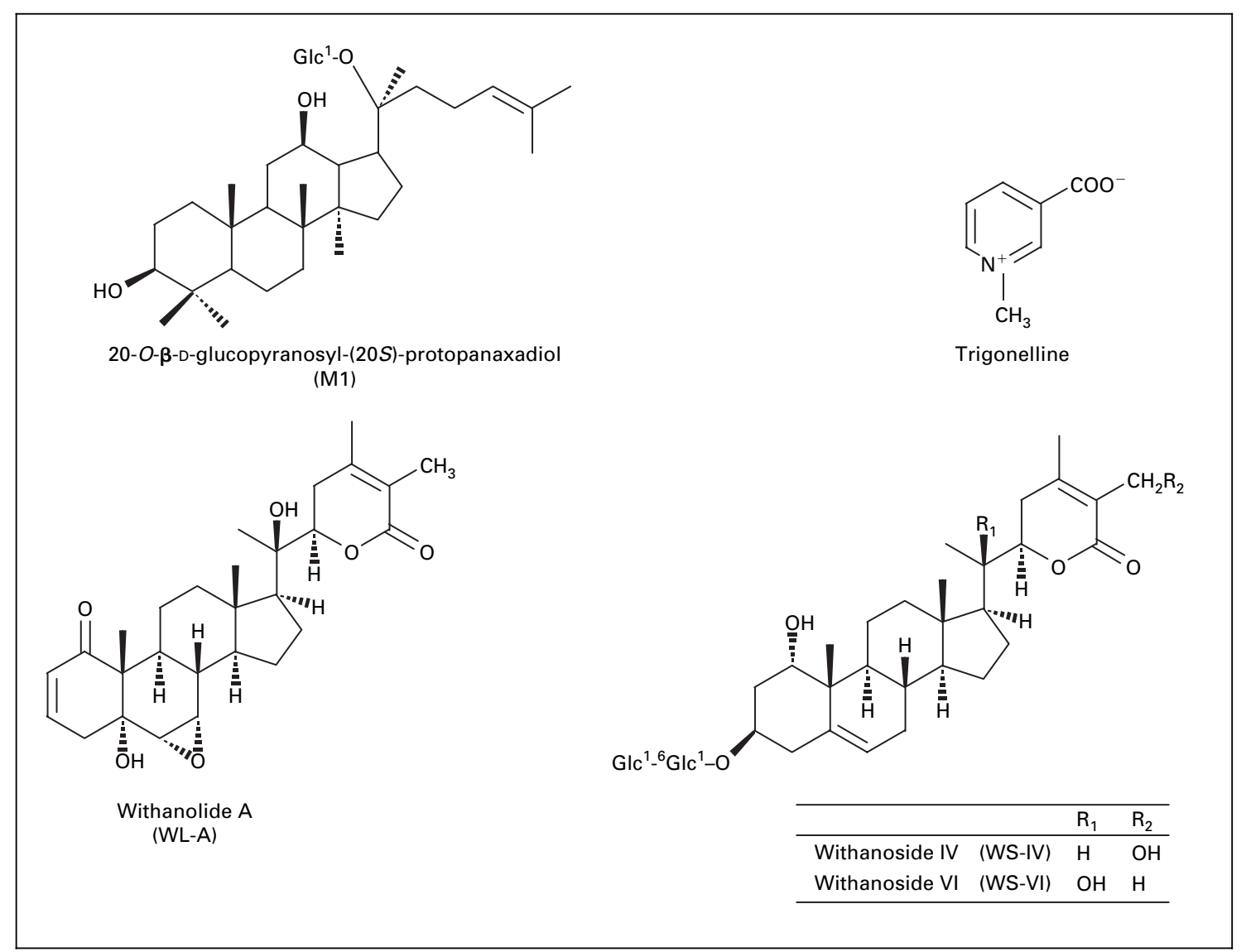

Fig. 1. Chemical structures of compounds that regenerate the neuronal network.

After the retention test, the expression levels of phosphorylated NF-H (axonal marker), synaptophysin (synaptic marker) and MAP2 (dendritic marker) were measured in mouse brains. We observed two cortical areas (parietal cortex and temporal cortex) and three hippocampal areas (CA1, CA3, and the dentate gyrus), as it is known that synaptic loss occurs primarily in the cerebral cortex and hippocampus in $\mathrm{AD}$ patients $[22,23]$ and in $\mathrm{AD}$ model mice [24]. The phosphorylated NF-H levels were remarkably reduced in these five areas of the brain in $A \beta(25-$ 35 )-injected compared with saline-injected mice (fig. 3a). Significant decreases were seen in the parietal cortex, CA1 and CA3; however, the expression levels of phosphorylated NF-H were nearly equal to those of the control in ginsenoside $\mathrm{Rb}_{1}$ - and M1-treated mice. Donepezil treatment had no effect on the levels of phosphorylated NF-H. The synaptophysin levels were also reduced in these five areas of the brain in $A \beta(25-35)$-injected compared with salineinjected mice (fig. 3b). Significant decreases were seen in the temporal cortex and CA1. In all areas, the synaptophysin levels were almost equal to or higher than control levels in ginsenoside $\mathrm{Rb}_{1}$ - and M1-treated mice. Donepezil treatment had no effect on the synaptophysin levels. The MAP2 levels were also reduced in the cerebral cortex and $\mathrm{CA} 1$ of the brain in $A \beta(25-35)$-injected compared with saline-injected mice (fig. 3c). Significant decreases were seen in the temporal cortex; however, these decreases in the expression levels of MAP2 were not clearly recovered by ginsenoside $\mathrm{Rb}_{1}, \mathrm{M} 1$ or donepezil. Although treatment with M1 tended to increase the MAP2 level in the temporal cortex, the effect was weak. No differences in neuronal density were observed among the groups in any brain areas. Treatment with M1, a metabolite of ginsenoside $\mathrm{Rb}_{1}$, results in the recovery of impaired learning and memory in $A \beta(25-35)$-injected mice with degenerated axons and synapses. The maintained retention of spatial memory was also seen after the discontinuation of ginsenoside $\mathrm{Rb}_{1}$ and $\mathrm{M} 1$ administration. These results 


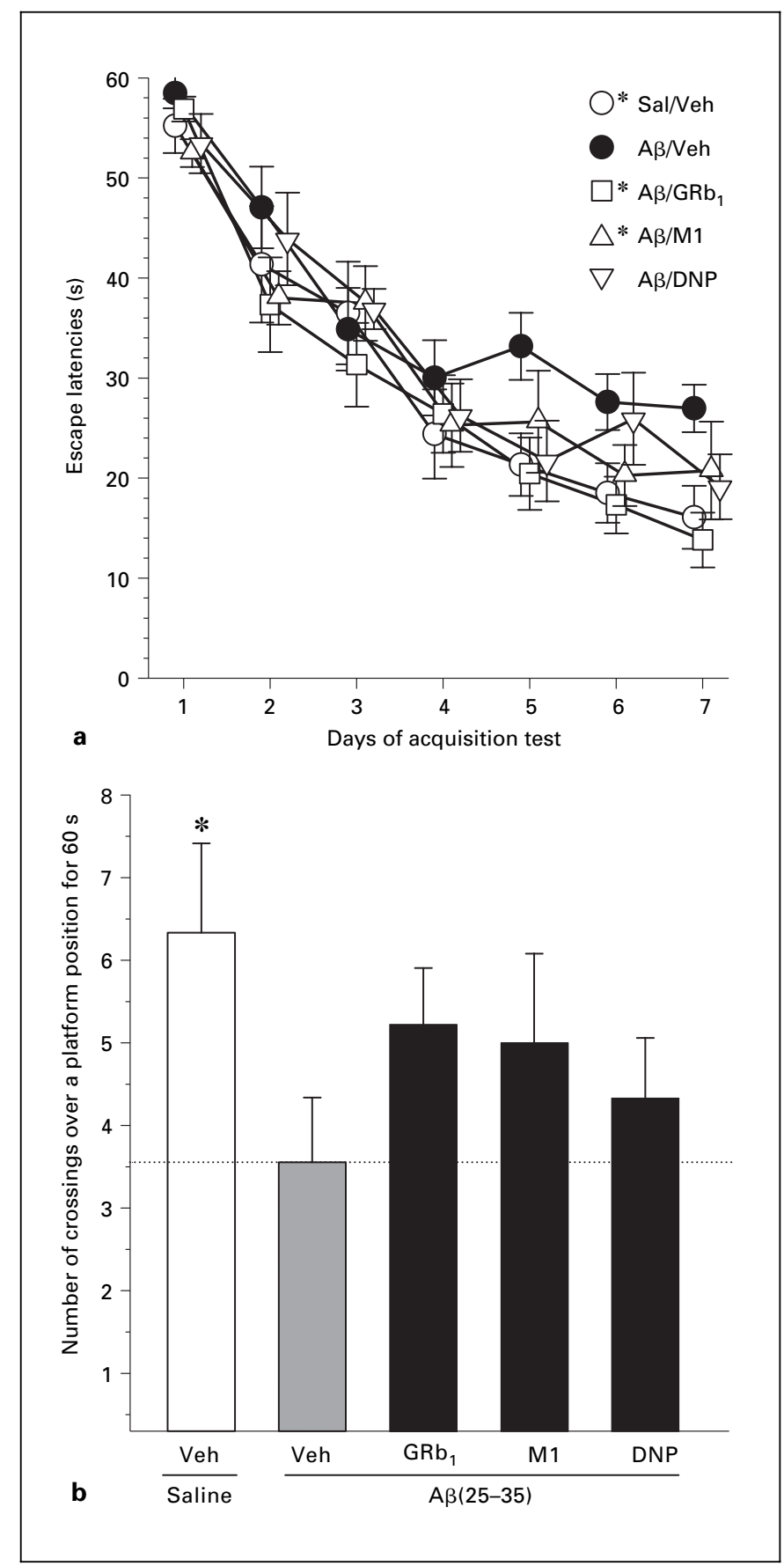

Fig. 2. Effects of ginsenoside $R b_{1}$ and $M 1$ on the impairment of spatial memory induced by $\mathrm{A} \beta(25-35)$ injection. a Escape latencies per group in four trials were tested in a Morris water maze over 7 days. Vehicle was administered p.o. to saline-i.c.v.-injected mice. To $\mathrm{A} \beta(25-35)$-i.c.v.-injected mice $(5 \mathrm{nmol})$, the vehicle, ginsenoside $\mathrm{Rb}_{1}$ $(10 \mu \mathrm{mol} / \mathrm{kg}), \mathrm{M} 1(10 \mu \mathrm{mol} / \mathrm{kg})$, or donepezil $(0.5 \mathrm{mg} / \mathrm{kg})$ was administered p.o. for 14 days. Values represent the means and SEM of 9 mice. ${ }^{*} \mathrm{p}<0.05$ when compared with the $A \beta(25-35)$ plus vehicletreated group. Two-way repeated measure analysis of variance was carried out, followed by Dunnett's post hoc test. b The number of crossings over the previous position of a platform had previously suggest that ginsenoside $R b_{1}$ and $M 1$ may induce the structural repair of neuronal connections.

In the rat large intestine, ginsenoside $\mathrm{Rb}_{1}$ is completely metabolized to M1 $3 \mathrm{~h}$ after administration [25]. In mice, only M1 is continuously detected in the blood from 30 min to $16 \mathrm{~h}$ after oral administration of ginsenoside $\mathrm{Rb}_{1}$ [26]. In humans, M1 is detected in plasma from $7 \mathrm{~h}$ after the ingestion of Ginseng, and in urine from $12 \mathrm{~h}$ after intake, and aglycone is not detected in either plasma or urine [20]. These results suggest that M1 is the final metabolite of ppd-type saponins. The recovery potency in $\mathrm{A} \beta(25-35)$-injected mice by p.o.-administered ginsenoside $\mathrm{Rb}_{1}$ and $\mathrm{M} 1$ was almost identical, indicating that the majority of orally administered ginsenoside $\mathrm{Rb}_{1}$ was metabolized into M1. Considering that most ppd-type saponins are metabolized to M1, which is the active principal, the total content of ppd-type saponins is possibly an important index of the anti-AD activity of Ginseng.

\section{Effect of M1 on AB(25-35)-Induced Axonal Atrophy in Rat Cortical Neurons}

In in vitro experiments, M1 demonstrated an axonal regeneration effect. To investigate the $A \beta(25-35)$-induced damage to the neuronal network and the reconstructive activity of drugs, $10 \mu M \mathrm{~A} \beta(25-35)$ was added to the cortical neurons on day 7 , and after 3 days the medium was replaced by fresh medium, including drugs. Although the cortical neurons connected with each other during the 7day culture, some of the connections were lost 3 days after $\mathrm{A} \beta(25-35)$ treatment. At 4 days, both phosphorylated NF-H-positive (fig. 4a) and MAP2-positive (fig. 4b) neurites were significantly shortened by $A \beta(25-35)$ treatment. Treatment with $0.01 \mu M \mathrm{M} 1$ (to $78.5 \%$ of the control) significantly increased the recovery of the length of phosphorylated NF-H-positive neurites (fig. 4a), while MAP2-positive neurites were not extended (fig. 4b). NGF significantly enhanced the lengths of phosphorylated NF-

been measured over $60 \mathrm{~s}, 6$ days after the last acquisition test. This was also 6 days after the discontinuance of drug treatment. Vehicle was administered p.o. to saline-i.c.v.-injected mice. To A $\beta(25-35)-$ i.c.v.-injected mice, vehicle (Veh), ginsenoside $\mathrm{Rb}_{1}\left(\mathrm{GRb}_{1}\right)$, $\mathrm{M} 1$, or donepezil (DNP) was administered p.o. Values represent the means and SEM of 9 mice. $*$ p $<0.05$ when compared with the $A \beta(25-35)$ plus vehicle-treated group. One-way analysis of variance was carried out, followed by Dunnett's post hoc test. 
Fig. 3. Effects of ginsenoside $R b_{1}$ and $M 1$ on axonal atrophy and synaptic loss induced by $A \beta(25-35)$ injection. Expression levels of phosphorylated NF-H (a), synaptophysin (b) and MAP2 (c) in brain slices were quantified. Vehicle was administered p.o. to saline-i.c.v.-injected mice. To $A \beta(25-35)-$ i.c.v.-injected mice, vehicle, ginsenoside $\mathrm{Rb}_{1}$ $(10 \mu \mathrm{mol} / \mathrm{kg}), \mathrm{M} 1(10 \mu \mathrm{mol} / \mathrm{kg})$, or donepezil $(0.5 \mathrm{mg} / \mathrm{kg})$ was administered p.o. for 14 days. The parietal cortex (PC), temporal cortex (TC), hippocampal CA1 and CA3, and dentate gyrus (DG) were observed. The fluorescence intensities of six areas in each slice were measured. Values represent the means and SEM of three mice. ${ }^{*} \mathrm{p}<0.05$ when compared with the $A \beta(25-35)$ plus vehicletreated group. One-way analysis of variance was carried out, followed by Dunnett's post hoc test.
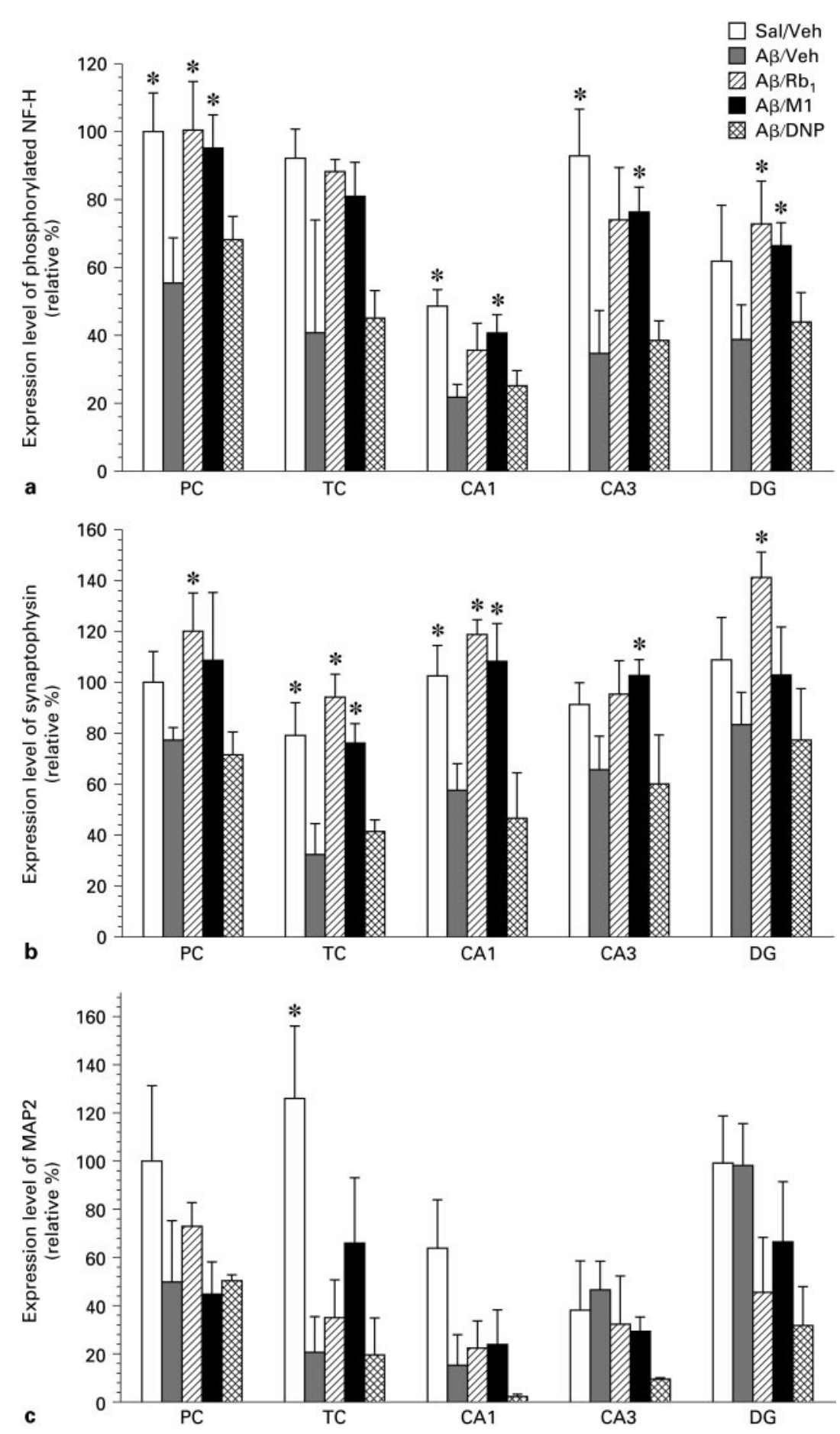


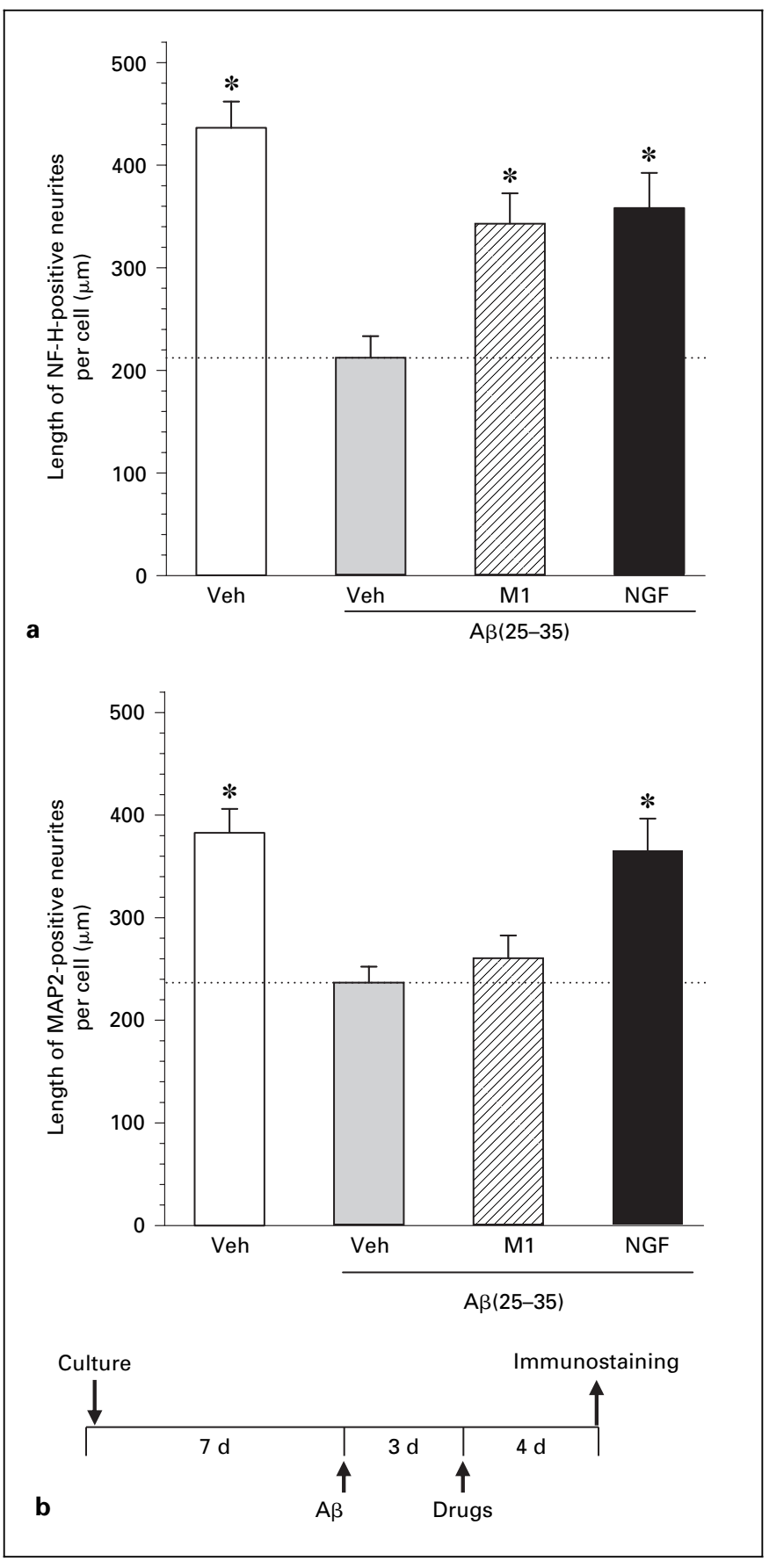

Fig. 4. Effect of post-treatment with $M 1$ on $A \beta(25-35)$-induced axonal and dendritic atrophy. $\mathrm{A} \beta(25-35)(10 \mu M)$ was added to rat cortical neurons at 7 days in vitro. Three days later, the medium was replaced by new medium containing M1 $(0.01 \mu M)$, NGF (100 ng/ $\mathrm{ml}$ ) or the vehicle (Veh, DMSO). Four days later, the cells were fixed and immunostained for phosphorylated NF-H (a) and MAP2 (b). The lengths of neurites positive for phosphorylated NF-H or MAP2 per cell were measured. Values represent the means and SEM of 30 cells. ${ }^{*} \mathrm{p}<0.05$ when compared with the $\mathrm{A} \beta(25-35)$ plus vehicletreated group. One-way analysis of variance was carried out, followed by Dunnett's post hoc test.
H-positive (to $82.0 \%$ of the control) and MAP2-positive (to $95.3 \%$ of the control) neurites. In addition, M1 increased in pre-synaptic density to the control level after $\mathrm{A} \beta(25-35)$-induced synaptic loss occurred [our unpublished data].

Neuritic atrophy by $A \beta(1-40)$ and $A \beta(25-35)$ has been reported in chick sympathetic neurons [27] and rat cortical neurons [28]. As neurite atrophy is thought to be due to unusual cell adhesion [27, 29], M1 may be capable of normalizing the adhesive mechanism. Although $A \beta$ is known to cause neuronal death through increased $\left[\mathrm{Ca}^{2+}\right]$ neurons [30], increased peroxynitrites in microglias [31], and mitochondrial dysfunction in neurons [32], the death pathway has been shown to be mediated by separate molecular mechanisms of a neuritic dystrophy event [2729]. Since ginsenoside $\mathrm{Rb}_{1}$ did not inhibit neuronal death induced by $A \beta(25-35)$, the mechanism of rescuing axonal atrophy may not be identical to that for recovery from $\mathrm{A} \beta$-induced neuronal death.

\section{Ashwagandha}

\section{Neurite Outgrowth with Methanol Extract and Isolated} Withanolides

Ashwagandha (root of Withania somnifera Dunal) is the most popular herbal drug in Ayurvedic medicine, and has been used traditionally and commonly as a tonic and nootropic agent. It has also been reported as associated with improvements in scopolamine-induced memory deficits in mice [33]. Treatment with a methanol extract of Ashwagandha induced neurite extension [34]. We further identified 6 withanolide derivatives from methanol extract (withanolide A, withanoside IV, withanoside VI, etc.; fig. 1), which induced neurite outgrowth in human neuroblastoma SH-SY5Y cells [35]. In normal cortical neurons, the predominant dendritic outgrowth was induced by treatment with withanoside IV or withanoside VI, whereas predominant axonal outgrowth was observed in treatment with withanolide $\mathrm{A}$ in normal cortical neurons [36].

\section{Effect of Withanolides on A $\beta(25-35)$-Induced Neuritic Atrophy and Synaptic Loss}

In $A \beta(25-35)$-induced damaged cortical neurons, withanolide A, withanoside IV, and withanoside VI showed neuritic regeneration and synaptic reconstruction. $24 \mathrm{~h}$ after culture initiation, $10 \mu M \mathrm{~A} \beta(25-35)$ was added to the culture medium simultaneously with the drugs. Four days later, $A \beta(25-35)$ treatment significantly 
Fig. 5. Effects of withanolide A, withanoside $\mathrm{IV}$, and withanoside VI on the prevention of $A \beta(25-35)$-induced dendritic and axonal atrophy. Cortical neurons were cultured for $24 \mathrm{~h}$, and then the cells were treated simultaneously with $10 \mu M \mathrm{~A} \beta(25-35)$, and withanolide A (WL-A), withanoside IV (WS-IV), or withanoside VI (WS-VI) at a concentration of $1 \mu M$; or NGF or BDNF at a concentration of $100 \mathrm{ng} / \mathrm{ml}$; or vehicle (Veh); or with vehicle alone (Cont). Four days after treatment, the cells were fixed and immunostained for MAP2 or phosphorylated NFH. Lengths of MAP2-positive neurites (a) and phosphorylated NF-H-positive neurites (b) were measured in each treatment. The values represent the means and SEM of 30 cells. $* \mathrm{p}<0.05$ when compared with the $\mathrm{A} \beta(25-35)$ plus vehicle-treated group. Oneway analysis of variance was carried out, followed by Dunnett's post hoc test.

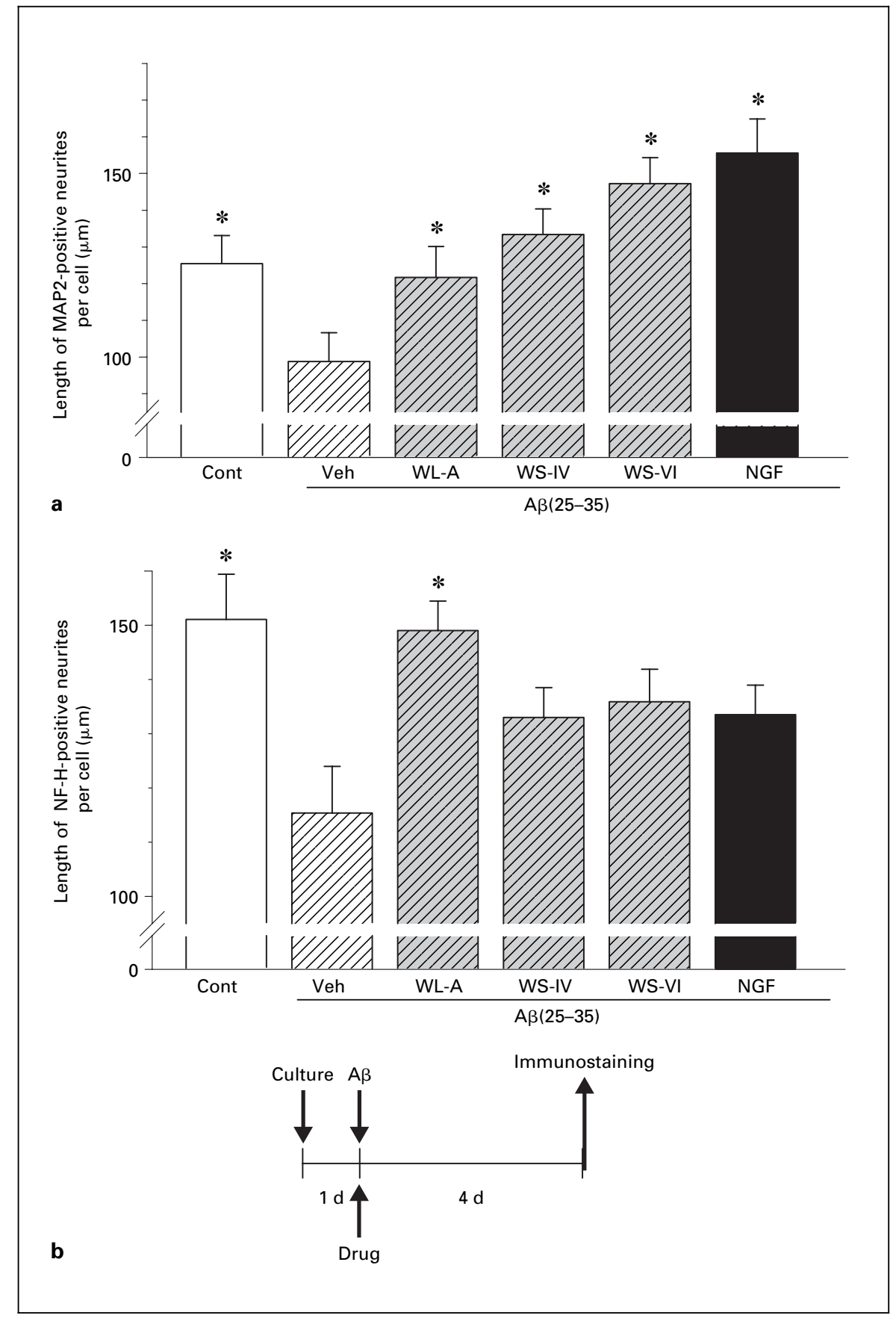

inhibited the outgrowth of both MAP2-positive neurites and phosphorylated NF-H-positive neurites, showing that $A \beta(25-35)$ induced both dendritic and axonal atrophy in rat cortical neurons. Simultaneous treatment with $A \beta(25-$ 35) and withanolide A, withanoside IV, or withanoside VI at a concentration of $1 \mu M$ prevented both dendritic and axonal atrophy induced by $A \beta(25-35)$. Dendritic atrophy was completely prevented by treatment with withanolide A $(97.0 \%$ of the control), withanoside IV (106.3\% of the control), or withanoside VI (117.4\% of the control) (fig. 5a). In particular, treatment with withanosides IV and VI tended to induce the growth of longer dendrites than treatment with withanolide A. 


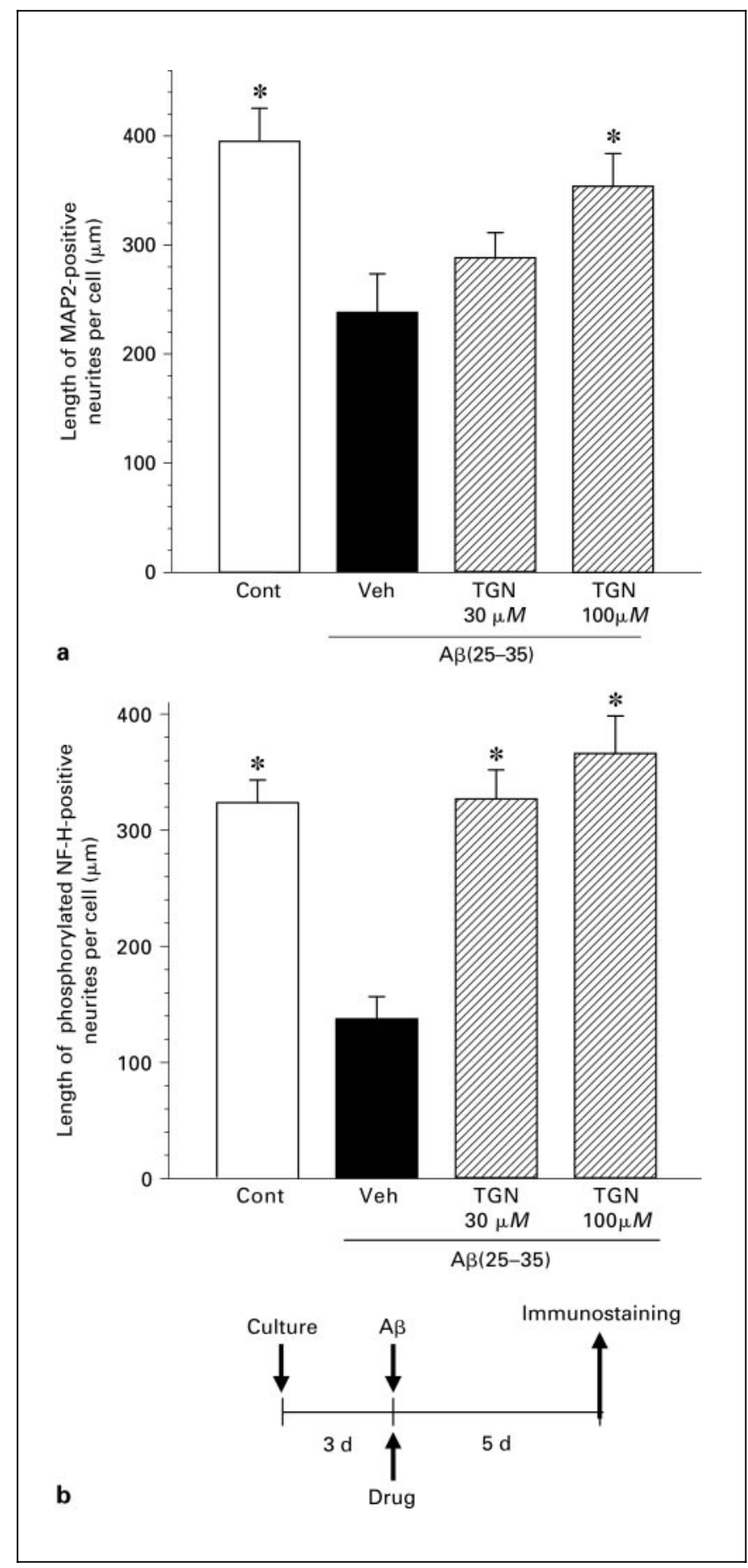

Fig. 6. The effect of trigonelline on the prevention of $\mathrm{A} \beta(25-35)-$ induced dendritic and axonal atrophy. Cortical neurons were cultured for 3 days, and then the cells were treated simultaneously with $10 \mu M \mathrm{~A} \beta(25-35)$, and trigonelline at a concentration of 30 or $100 \mu M$, or vehicle (Veh), or with the vehicle alone (Cont). Five days after treatment, the cells were fixed and immunostained for MAP2 or
Axonal atrophy was partially prevented by treatment with withanoside IV (88.0\% of the control) and withanoside VI $(90.0 \%$ of the control), whereas treatment with withanolide A ( $98.6 \%$ of the control) completely prevented axonal atrophy (fig. 5b).

To determine whether regenerated neurites are able to reconstruct synapses, the expressions of synaptic markers were investigated. Rat cortical neurons were cultured for 21 days to construct mature synapses in vitro, and after the culture period, $A \beta(25-35)$ was added to the samples. Four days later, the cells were immunostained with an antibody for post-synaptic density, (PSD)-95 (post-synaptic marker), or with synaptophysin (pre-synaptic marker). PSD-95- and synaptophysin-positive puncta were significantly decreased by treatment with $A \beta(25-35)$ [37]. Withanolide A, withanoside IV, withanoside VI, or NGF was added to the culture medium after 4 days of treatment with $A \beta(25-35)$ after synaptic loss had occurred. Seven days after the addition of the drug, the cells were fixed and immunostained for PSD-95 or synaptophysin. Treatment with withanolide A, withanoside IV, or withanoside VI significantly induced both PSD-95 and synaptophysin expression, as compared with treatment with the vehicle. These results indicate that withanolide A, withanoside IV, and withanoside VI facilitated the reconstruction of both post-synaptic and pre-synaptic regions in neurons in which severe synaptic loss had already occurred. This increase in post-synaptic structures tended to be significant following treatment with withanoside IV $(86.0 \%$ of the control) and withanoside VI (83.6\% of the control), as compared with withanolide A treatment $(68.0 \%$ of the control). However, reconstruction of the pre-synaptic region was induced significantly and markedly by treatment with withanolide A (108.1\% of the control), as compared with withanoside IV ( $81.3 \%$ of the control) and withanoside VI ( $75.8 \%$ of the control) treatments. Treatment with NGF did not lead to an increase in the development of either the post-synapses ( $57.7 \%$ of the control) or the presynapses (54.4\% of the control).

phosphorylated NF-H. Lengths of MAP2-positive neurites (a) and phosphorylated NF-H-positive neurites (b) were measured in each treatment. The values represent the means and SEM of 12-20 cells (a) or 14-22 cells $(\mathbf{b}){ }^{*} \mathrm{p}<0.05$ when compared with the $\mathrm{A} \beta(25-35)$ plus vehicle-treated group. One-way analysis of variance was carried out, followed by Dunnett's post hoc test. 
Although NGF extended both axons and dendrites (fig. 4, 5), it has no effect on synaptogenesis. Since NGF itself is not able to pass through the blood-brain barrier, low-molecular-weight substances that mimic NGF action have been developed as anti-dementia drugs. However, such NGF-like drugs are not expected to cure dementia because of a lack of synaptogenesis activity.

\section{Coffee Beans}

\section{Neurite Outgrowth with Trigonelline}

Coffee is consumed as a drink, and is known to stimulate the central nervous system as well as the heart and circulation [38]. It is thought that these effects are mainly caused by caffeine [39] but the effects of other coffee constituents on the central nervous system have hardly been reported. Coffee beans are crude drugs, used in the traditional system of Unani medicine [40].

Among the extracts of raw and roasted coffee beans, a methanol-soluble fraction of the ethanol extract $(1 \mu \mathrm{g} / \mathrm{ml})$ of raw beans significantly increased the percentage of cells with neurites in human neuroblastoma SK-N-SH cells [41]. It was demonstrated that the neurite outgrowth activity of the methanol fraction decreased depending on the extent of roasting. Among subfractions of this methanol fraction, the basic fraction had significant neurite outgrowth activity. In this basic fraction, trigonelline was identified as an active constituent (fig. 3). It is known that a decrease in trigonelline is related to the degree of roasting [42].

In rat cortical neurons, trigonelline showed dendritic and axonal regeneration. Three days after initiation of the culture, $A \beta(25-35)$ was added to the culture medium with trigonelline. Trigonelline (30 and $100 \mu M)$ treatment dose-dependently prevented both dendritic (fig. 6a) and axonal (fig. 6b) atrophy induced by $\mathrm{A} \beta(25-35)$.

\section{Effect of Trigonelline on A $\beta(25-35)$-Induced Memory Impairment}

Fourteen days after the i.c.v. injection of $A \beta(25-35)$ in male ddY mice (6 weeks old), trigonelline $(500 \mathrm{mg} / \mathrm{kg})$, donepezil hydrochloride $(0.5 \mathrm{mg} / \mathrm{kg})$, or the vehicle (tap water) was administered orally once daily for 15 days. Mice were trained in the water maze for 5 days, starting 21 days after the i.c.v. administration of $A \beta(25-35)$. Six days after the last acquisition test, the retention test was performed (fig. 7). The number of crossings over a previous platform position was significantly decreased in the $\mathrm{A} \beta(25-35)$-injected group compared with the saline-in-

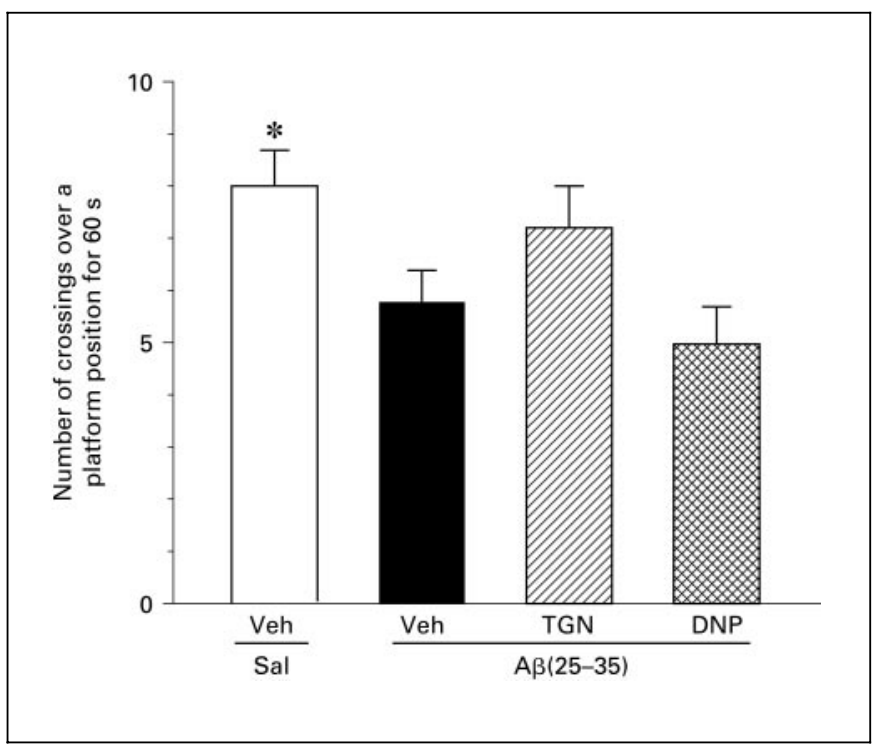

Fig. 7. Effect of trigonelline on the impairment of spatial memory induced by $A \beta(25-35)$ injection. The number of crossings over the previous position of a platform was measured over $60 \mathrm{~s}, 6$ days after the last acquisition test in a Morris water maze. This was also 6 days after the discontinuance of drug treatment. Vehicle was administered p.o. to saline-i.c.v.-injected mice. To $A \beta(25-35)$-i.c.v.-injected mice ( $4.7 \mathrm{nmol}$ ), the vehicle (Veh), $500 \mathrm{mg} / \mathrm{kg}$ trigonelline (TGN), or $0.5 \mathrm{mg} / \mathrm{kg}$ donepezil (DNP) was administered p.o. Values represent the means and SEM of 9 mice. $* \mathrm{p}<0.05$ when compared with the $\mathrm{A} \beta(25-35)$ plus vehicle-treated group. One-way analysis of variance was carried out, followed by Dunnett's post hoc test.

jected group. The number of crossings was recovered by treatment with trigonelline, suggesting that memory retention is improved by trigonelline.

\section{Conclusions}

The ppd-type saponins of Ginseng drugs and M1 (a metabolite of ppd-type saponins by intestinal bacteria) induced significant recovery from memory impairment, axonal atrophy and synaptic loss in mice. The effect of M1 on axonal reconstruction was further confirmed in cultured cortical neurons. These results suggest that orally administered ppd-type saponins potentially ameliorate dementia by reconstructing the neuronal network. Withanolide A, withanoside IV, and withanoside VI, which were isolated from Ashwagandha, facilitated the regeneration of dendrites and axons, and led to the dramatic construction of synapses, although the neuron damage was 
profound and severe. Trigonelline also had dendritic and axonal regeneration activity, and improved memory retention. These compounds, sourced from natural products, and used with treatments preventing pathogenesis and neuronal death, are expected to play an important role as new categorized drugs in curing neurodegenerative diseases in the near future. Although we have shown the high potential of neuronal regeneration from compounds isolated from Ginseng drugs, Ashwagandha and coffee beans, it is dangerous to simply imply that these herbal drugs are expected to be excellent anti-dementia drugs. When taking herbal drugs, the risk of side effects brought by other constituents, and sufficient efficacy compared with isolated compounds should be investigated and carefully considered. However, drugs used in traditional med- icine may offer a treasury of new medicines to treat intractable diseases with the use of novel study concepts and the application of objective scientific analyses.

\section{Acknowledgments}

We thank Prof. M. Hattori, Dr. K. Zou, Mr. N. Matsumoto, Dr. M. R. Meselhy, Dr. N. Nakamura and Dr. J. Zhao of the Institute of Natural Medicine, Toyama Medical and Pharmaceutical University for their extensive contribution to this study. This work was supported by Kampou Science Foundation, Uehara Memorial Foundation, Grants-in-Aid for Scientific Research (B), No. 11695086 in 19992001 and No. 14406030 in 2002-2004 from the Japan Society for the Promotion of Science, and the 21st Century COE Program of the Ministry of Education, Culture, Sports, Science and Technology, Japan.

\section{References}

1 Ogura H, Kosasa T, Kuriya Y, Yamanishi Y: Donepezil, a centrally acting acetylcholinesterase inhibitor, alleviates learning deficits in hypocholinergic models in rats. Methods and Findings in Exp Clin Pharmacol 2000;22:8995.

2 DeKosky S, Scheff SW: Synapse loss in frontal cortex biopsies in Alzheimer's disease: Correlation with cognitive severity. Ann Neurol 1990; 27:457-464

\3 Terry RD, Masliah E, Salmon DP, Butters N, DeTeresa R, Hill R, et al: Physical basis of cognitive alterations in Alzheimer's disease: Synapse loss is the major correlate of cognitive impairment. Ann Neurol 1991;30:572-580.

-4 Dickson TC, Vickers JC: The morphological phenotype of $\beta$-amyloid plaques and associated neuritic changes in Alzheimer's disease. Neuroscience 2001;105:99-107.

-5 Jackson M, Gentleman S, Lennox L, Ward L, Gray T, Randall K, et al: The cortical neuritic pathology by Huntington's disease. Neuropathol Appl Neurobiol 1995;21:18-26.

6 Mattila PM, Rinne JO, Helenius H, Roytta M: Neuritic degeneration in the hippocampus and amygdala in Parkinson's disease in relation to Alzheimer pathology. Acta Neuropathol 1999; 98:157-164

7 Liberski PP, Budka H: Neuroaxonal pathology in Creutzfeldt-Jakob disease. Acta Neuropathol 1999;97:329-334.

8 Zhao R, MaDaniel WF: Ginseng improves strategic learning by normal and brain-damaged rats. NeuroReport 1998;9:1618-1624.

9 Zhong YM, Nishijo H, Uwano T, Tamura R, Kawanishi K, Ono T: Red Ginseng ameliorated place navigation deficits in young rats with hippocampal lesions and aged rats. Physiol Behav 2000;69:511-525.
10 Mook-Jung I, Hong HS, Boo JH, Lee KH, Yun SH, Cheong MY, Joo I, Huh K, Jung MW: Ginsenoside $R b_{1}$ and $R g_{1}$ improve spatial learning and increase hippocampal synaptophysin level in mice. J Neurosci Res 2001;63:509-515.

$>11$ Sugaya A, Yuzurihara M, Tsuda T, Yasuda K, Kajiwara K, Sugaya E: Proliferative effect of Ginseng saponin on neurite extension of primary cultured neurons of the rat cerebral cortex. J Ethnopharmacol 1988;22:173-181.

12 Saito H, Suda K, Schwab M, Thoenen H: Potentiation of the NGF-mediated nerve fiber outgrowth by ginsenoside $\mathrm{Rb}_{1}$ in organ cultures of chicken dorsal root ganglia. Jpn J Pharmacol 1977;27:445-451.

13 Nishiyama N, Cho SI, Kitagawa I, Saito H: Malonylginsenoside $\mathrm{Rb}_{1}$ potentiated nerve growth factor (NGF)-induced neurite outgrowth of cultured chick embryonic dorsal root ganglia. Biol Pharm Bull 1994; 17:509-513.

14 Tohda C, Matsumoto N, Zou K, Meselhy RM, Komatsu K: Axonal and dendritic extension by protopanaxadiol-type saponins from Ginseng drugs in SK-N-SH cells. Jpn J Pharmacol 2002; 90:254-262.

15 Zou K, Zhu S, Tohda C, Cai SQ, Komatsu K: Dammarane-type triterpene saponins from $\mathrm{Pa}$ nax japonicus. J Natural Products 2002;65: 346-351.

16 Zou K, Zhu S, Meselhy RM, Tohda C, Cai SQ, Komatsu K: Dammarane-type saponins from Panax japonicus and their neurite outgrowth activity in SK-N-SH cells. J Natural Products 2002;65:1288-1292.

17 Zou K, Zhu S, Cai SQ, Komatsu K: In Ye San Qi, Kou Zi Qi: Constituents from the underground part of Panax plants. Abstract 121th Ann Meet Pharmaceutical Soc Japan, 2001, p 110.
18 Zhu S, Zou K, Fushimi H, Cai SQ, Komatsu K: Comparative study on triterpene saponins of Ginseng drugs. Planta Medica 2004;70:666677.

19 Odani T, Tanizawa H, Takino Y: Studies on the absorption, distribution, excretion and metabolism of Ginseng saponins. III. The absorption, distribution and excretion of ginsenoside $\mathrm{Rb}_{1}$ in the rat. Chem Pharm Bull 1983;31: 1059-1066.

20 Tawab MA, Bahr U, Karas M, Wurglics M, Schubert-Zsilavecz M: Degeneration of ginsenosides in humans after oral administration. Drug Metab Dispos 2003;31:1065-1071.

-21 Tohda C, Matsumoto N, Zou K, Meselhy RM, Komatsu K: A $\beta(25-35)$-induced memory impairment, axonal atrophy, and synaptic loss are ameliorated by M1, a metabolite of protopanaxadiol-type saponins. Neuropsychopharmacology 2004;29:860-868.

22 DeKosky ST, Scheff SW: Synapse loss in frontal cortex biopsies in Alzheimer's disease: Correlation with cognitive severity. Ann Neurol 1990;27:457-464.

$\checkmark 23$ Heinonen O, Soininen H, Sorvari H, Kosunen O, Paljarvi L, Koivisto E, Riekkinen PJ Sr: Loss of synaptophysin-like immunoreactivity in the hippocampal formation is an early phenomenon in Alzheimer's disease. Neuroscience 1995;64:375-384.

24 Games D, Adams D, Alessandrini R, Barbour R, Berthelette P, Blackwell C, Carr T, Clemens J, Donaldson T, Gillespie F, Guido T, Hagopian S, Johnson-Wood K, Khan K, Lee M, Leibowitz P, Lieberburg I, Little S, Masliah E, McConlogue L, Montoya-Zavala M, Mucke L, Paganini L, Penniman E, Power M, Schenk D, Seubert P, Snyder B, Soriano F, Tan H, Vitale J, Wadsworth S, Wolozin B, Zhao J: Alzheimer-type neuropathology in transgenic mice overexpressing V717F 3 -amyloid precursor protein. Nature 1995;373:523-527. 
25 Karikura M, Miyase T, Tanizawa H, Taniyama $\mathrm{T}$, Takino Y: Studies on absorption, excretion and metabolism of Ginseng saponons. VII. Comparison of the decomposition of ginsenoside- $R b_{1}$ and $-R b_{2}$ in the digestive tract of rats. Chem Pharm Bull 1991;39:2357-2361.

26 Hasegawa H, Sung J-H, Benno Y: Role of human intestinal Prevotella oris in hydrolyzing Ginseng saponins. Planta Medica 1997;63: 436-440.

27 Postuma RB. He W, Nunan J, Beyreuther K, Masters CL, Barrow CJ, Small DH: Substratebound beta-amyloid peptides inhibit cell adhesion and neurite outgrowth in primary neuronal cultures. J Neurochem 2000;74:11221130.

28 Grace EA, Rabiner CA, Busciglio: Characterization of neuronal dystrophy induced by fibrillar amyloid beta: Implications for Alzheimer's disease. J Neurosci 2002;114:265-273.

29 Grace EA, Busciglio J: Aberrant activation of focal adhesion proteins mediates fibrillar amyloid $\beta$-induced neuronal dystrophy. J Neurosci 2003;23:493-502.

30 Lin H, Bhatia R, Lal R: Amyloid $\beta$ protein forms ion channels: implications for Alzheimer's disease pathophysiology. FASEB J 2001; 15:2433-2444.

31 Xie Z, Wei M, Morgan TE, Fabrizio P, Han D, Finch CE, Longo VD: Peroxynitrite mediates neurotoxicity of amyloid beta-peptide1-42and lipopolysaccharide-activated microglia. $\mathrm{J}$ Neurosci 2002;22:3484-3492.
32 Casley CS, Land JM, Sharpe MA, Clark JB, Duchen MR, Canevari L: $\beta$-Amyloid fragment $25-35$ causes mitochondrial dysfunction in primary cortical neurons. Neurobiol Dis 2002;10: 258-267.

33 Dhuley JN: Nootropic-like effect of Ashwagandha (Withania somnifera L.) in mice. Phytother Res 2001;15:524-528.

34 Tohda C, Kuboyama T, Komatsu K: Dendrite extension by methanol extract of Ashwagandha (roots of Withania somnifera) in SK-N-SH cells. NeuroReport 2000;11:1981-1985.

35 Zhao J, Nakamura N, Hattori M, Kuboyama $\mathrm{T}$, Tohda C, Komatsu K: Withanolide derivatives from the roots of Withania somnifera and their neurite outgrowth activities. Chem Pharm Bull 2002;50:760-765.

36 Kuboyama T, Tohda C, Zhao J, Nakamura N, Hattori M, Komatsu K: Axon- or dendrite-predominant outgrowth induced by constituents from Ashwagandha. NeuroReport 2002;13: 1715-1720.

37 Kuboyama T, Tohda C, Komatsu K: Neuritic regeneration and synaptic reconstruction induced by withanolide $\mathrm{A}$. $\mathrm{Br} \mathrm{J}$ Pharmacol 2005;144:961-971.

38 Czok G: Coffee and health (abstract in English). Z Ernährungswiss 1977;16:248-255.

39 Riedel W, Hogervorst E, Leboux R, Verhey F, van Praag H, Jolles J: Caffeine attenuates scopolamine-induced memory impairment in humans. Psychopharmacology 1995;122:158168.

40 Liu YM, Shawuti Y: Pharmacography of Uighur. Wulumuqi, Xinjiang People's Publishing House, 1985, p 267.
41 Tohda C, Nakamura N, Komatsu K, Hattori $\mathrm{M}$ : Trigonelline-induced neurite outgrowth in human neuroblastoma SK-N-SH cells. Biol Pharm Bull 1999;22:679-682.

42 Taguchi H: Biosynthesis and metabolism of trigonelline, and physiological action of the compound (abstract in English). Vitamins 1988;62: 549-557.

43 Fukuyama Y, Nakade K, Minoshima Y, Yokoyama R, Zhai H, Mitsumoto Y: Neurotrophic activity of honokiol on the cultures of fetal rat cortical neurons. Bioorg Med Chem Lett 2002; 12:1163-1166.

44 Hur JY, Lee P, Kim H, Kang I, Lee KR, Kim SY: (-)-3,5-Dicaffeoyl-muco-quinic acid isolated from Aster scaber contributes to the differentiation of PC12 cells: Through tyrosine kinase cascade signaling. Biochem Biophys Res Commun 2004;313:948-953.

45 Yamazaki M, Chiba K, Mohri T: Neuritogenesis effect of natural iridoid compounds on $\mathrm{PC} 12 \mathrm{~h}$ cells and its possible relation to signaling protein kinases. Biol Pharm Bull 1996;19. 791-795.

46 Li P, Matsunaga K, Yamakuni T, Ohizumi Y: Potentiation of nerve growth factor-action by picrosides I and II, natural iridoids, in PC12D cells. Eur J Pharmacol 2000;406:203-208.

47 Li P, Matsunaga K, Yamamoto K, Yoshikawa R, Kawashima K, Ohizumi Y: Nardosinone, a novel enhancer of nerve growth factor in neurite outgrowth from PC12D cells. Neurosci Lett 1999;273:53-56. 